\title{
Gender and Age Dimensions of Occupational Stress and Dissociative Features among IT Professionals
}

\author{
Arshia Rajshekhar ${ }^{1 *}$, Dr. Tissy Mariam Thomas ${ }^{2}$
}

Keywords: Gender, Age, Occupation, Stress, Dissociative, IT Professionals

"The man who doesn't relax and hoot a few hoots voluntarily, now and then, is in great danger of hooting hoots and standing on his head for the edification of the pathologist and trained nurse, a little later on."

-Elbert Hubbard

Looking at the various psychological illnesses that plague the common man with increasing frequency these days, experts in the field are beginning to rethink the classification of such disorders as purely based on pathological symptoms finding that they have non-pathological features/symptoms as well. Dissociation and its related aspects are known to be rooted inn onpathological factors and not just pathological factors. Dissociation is often described as experiencing mild detachment from an individual "surroundings to severe detachment from one’s physical and emotional environment. (Dell and O'Neil, 2009).

A lot of the disorders afflicting individuals today have a lot to do with the way they interact with their environment and their responses to it. The present research study aims to explore and study the effects of stress levels on the presence of dissociative features in IT professionals. Work related stress as observed has become a very common cause for illness, both physical and mental in recent times. Stress, being a negative emotional state, can affect the physiological and mental processes over time. Work related stress is the most common factor contributing to chronic stress. Chronic stress is a relatively prevalent stressor in an individual's environment that requires them to adapt to it as it is an inherent part of their personal environment. Working long hours, having strained relationships with colleagues and supervisors or bosses, etc. contribute to the experience of stress.

\footnotetext{
${ }^{1}$ Department of Psychology, Christ University Bangalore, India

${ }^{2}$ Assistant Professor, Department of Psychology, Christ University Bangalore, India *Corresponding Author

(C) 2015 I A Rajshekhar, T Thomas; licensee IJIP. This is an Open Access Research distributed under the terms of the Creative Commons Attribution License (http://creativecommons.org/licenses/by/2.0), which permits unrestricted use, distribution, and reproduction in any Medium, provided the original work is properly cited.
} 


\section{Dissociative Features}

Pierre Janet, a French hypnotist, is said to be the reason for the development of most of the dissociation theory as quoted by Carl Jung in his works. Janet, a French man was a philosopher, who came up the idea to use hypnosis as a method to study the various dissociative tendencies of the mind. Later, he started running a laboratory in Salpêtrière, Paris, where he continued with his research in the field of dissociative experiences and conditions, specifically the nature and treatment of the same. Janet used hypnosis as his investigative tool and choice of therapeutic intervention as he strongly believed that hypnosis was a form of dissociation owing to the extent of suggestibility involved in hypnosis. According to Janet, "Hypnotism may be defined as the momentary transformation of the mental state of an individual, artificially induced by a second person, and sufficing to bring about dissociations of personal memory"(Haule, 1986). This refers to the phenomenon of dissociation which, today is characterized by multiple personalities, or the simultaneous development of sub-personalities, or alter egos with memories that run parallel to the others ${ }^{\text {ee }}$, in ignorance of others, or even milder forms of dissociation which may include daily life experiences like not being able to remember events, not being able to recognize oneself or others, finding oneself in situations one doesn’t remember being in etc. Dissociative symptoms are often associated with exposure to traumatic stressors (Bremner et al., 1992; Koopman, Classen, and Spiegel, 1994; Marmar et al., 1994) and can be exacerbated by exposure to subsequent stressors (Bremner and Brett, 1996).Over time, several instruments have been developed for the purpose of diagnosing dissociative disorders and also for the purpose of measuring general symptoms, including the Dissociative Experiences Scale (DES) (Bernstein \& Putnam, 1988), Structured Clinical Interview for DSM-IIIR Dissociative Disorders (SCID-D) (Steinberg, Rounsaville, and Cicchetti, 1990) and Dissociative Disorders Interview Schedule (DDIS) (Ross, Joshie and Currie, 1990).The epidemiology of dissociation indicates towards

several studies that have shown that "dissociative disorders may have been previously under diagnosed and a much higher prevalence is encountered” (Foote et al. 2006).Dissociation as a concept is open to many assumptions as it encompasses a wide range of emotional states and behaviours and thus, may be prone to conceptual confusions. But on-going research studies in recent times are contributing progressively to the repository of knowledge on the epidemiology of dissociation amongst the population in general in order to identify cases of dissociation which may not be recognized. Hence, the research conducted also addresses the issue of recognizing dissociation as a by-product of daily hassles involved in the sphere of occupational life.

\section{Occupational Stress}

Occupational stress is in simple words the stress experienced on a job. "Occupational stress can occur when there is a discrepancy between the demands of the environment/workplace and an individual's ability to carry out and complete these demands" (U.S. National Institute for Occupational Health and Safety, 1999; Henry and Evans, 2008).Occupational stress is also 
defined as "a condition arising from the interaction of people and their jobs and characterized by changes within people that force them to deviate from their normal functioning” (Beehr and Newman, 1978).Stress-related disorders include various kinds of conditions like psychological impairment or disorders (like post-traumatic stress disorder, depression, dissociation, anxiety etc.), emotional strain in the form of job dissatisfaction, fatigue from working for long hours, tension owing to deadlines, maladaptive behaviours like aggression or taking out frustration on others for one's own shortcoming in their occupation, substance abuse stemming from constant tension and anxiety etc. Also, another impact of stress is that of cognitive impairment which may present itself in the form of problems in concentrating and memory (Thomas, Colligan and Higgins, 2006). Occupational stressors include work overload, ambiguity or rigidity in carrying out tasks assigned and the added factor of responsibility for not only one "sown work but others as well.

\section{Work Atmosphere in the Information Technology (IT) Industry: A stressor}

As observed and understood from surveys and personal interactions, it has been found that jobs as software engineers in IT companies in Bangalore, Karnataka, also known as the Silicon Valley of India, with their long working hours especially the night shifts are becoming a source of stress for many people employed in such companies. The IT sector today faces everincreasing competition which calls for stepping up the game of each and every aspect of the organizational structure of the industry and its components. The effect of this change is manifested in the work the employees of these companies are required to put in. The changes may include changes in managerial practices (Zuboff,1985), structure, strategies, technology etc. which requires the employees to alter their work and thereby, may increase stress levels caused due to changes in the occupational setting. The reason for the same is due to ambiguities and difficulties perceived by the individual in the job position. Just as the levels of stress differ from one person to another, stress levels differ from one job to another. Hence, some jobs are inherently more stressful than others. Stress is also known to fuel the start of dissociation (Morgan et al., 2001) although it's not clear whether it pertains to state or per traumatic dissociation or trait dissociation.

Occupational stress can be a cause for the rise of dissociative features in the people employed in the IT sector as the stress may act upon the individual to the extent of the person resorting to ego defense mechanisms which may allow them to escape from reality for a short while or during a fugue state.

Hence, these factors constitute the framework of the study conducted on the effects of stress on the presence of dissociative features in IT professionals. This is possible through the method of 
correlational study wherein it would be possible to study the extent to which stress levels, higher low, affects the mental state of a person, thereby, causing him/her to dissociate in more than one way (motor dissociation, identity dissociation, speech dissociation, dissociative features in day to day life etc.).

\section{SIGNIFICANCE OF THE STUDY:}

Stress as observed today, is one of the leading causes for mental illness in the general population. To be able to study the relation between stress and mental disorder, specifically dissociation in daily life would help expand on the symptoms and reasons for dissociation beyond what is already known. Stress levels as studied by various researchers, has been found to be higher in certain jobs and organizations as compared to other, thus, increasing the probability of the employees developing some form or the other of stress related disorders, anxiety disorders, dissociative disorders etc. Given the growing importance and high stress levels connected to the Information Technology (IT) industry, the present study focuses on the increasing levels of stress amongst Indian IT professionals originating at the workplace that could cause a person to experience mild to moderate to high dissociation that could progress to become pathological dissociation in lieu of appropriate psychological intervention. It seeks to identify cultural relevance of the psychological phenomenon of dissociation as research on the same is very limited in the Indian context. The study has the potential to expand research on the non- pathological features of dissociation which is still a developing construct. Also, it has significance as it may also help IT companies recognize the need for psychiatric intervention or general health or self-esteem building strategies depending on the extent of dissociation observed among employees (low, moderate, high or pathological dissociation). The other implications or significance of the research study is the opportunity for IT companies to make adjustments to their structure, strategies, management etc. in accordance to the findings of this study as it may present the opportunity to alter or reduce stress levels in the employees, thereby, possibly reducing the chances of development of dissociative experiences which may cause a person to dissociate at a low, moderate or high level, which in turn could affect the quality of work produced. Also, age and gender differences identified in terms of stress levels and dissociative experiences can also help organizations to develop specialize intervention programmes based on the various groups identified, targeting the welfare of that particular group depending on the identified problem areas.

\section{OBJECTIVES OF THE STUDY:}

- To assess the stress levels of IT professionals.

- To explore the presence of dissociative features in IT professionals.

- To study the relation between stress levels and the presence of dissociative features in IT professionals.

- To compare gender and age differences in occupational stress and dissociative experiences. 


\section{HYPOTHESES:}

1. Stress levels are related to the presence of dissociative features in IT professionals.

2. There is no gender difference in occupational stress and dissociative features.

3. There is no age difference in occupational stress and dissociative features.

\section{REVIEW OF LITERATURE}

Although the concept of dissociation was introduced in the field of psychiatry by the end of the $19^{\text {th }}$ century by Pierre Janet, the term dissociation "as such still lacks a clear conceptualization or framework to work with. Owing to the clinical significance of dissociative psychopathology, many efforts have been made in the past few years to provide more clarity on the framework of dissociation. The study conducted attempts to understand the relationship between stress levels and the presence of dissociative features in IT professionals resulting from the same. Also, the study explores the domain of non-pathological symptoms of dissociation in a general population as there is no link between non pathological symptoms and dissociative disorders that has been identified as of now. The review of the following studies seeks to support the study conducted in the application of the theories and concepts applied in the following studies to the one being conducted.

\section{DISSOCIATION}

In a research study done by Maaranen (2004) titled „Factors associated with pathological dissociation in the general population ${ }^{e e}$, the prevalence of the same was studied, also the study focused on assessing the relationship between pathological dissociation and sociodemographic and several psychiatric variables was assessed. The sample used was a stratified sample of 2001subjects. The tools used were the Dissociative Experiences Scale, the Dissociative Experiences Scale-Taxon, the Toronto Alexithymia Scale, the Beck Depression Inventory and sociodemographic background. The findings of the study conducted by Maaranen (2004) were that pathological dissociation was found to be strongly related to incidents of depression, alexithymia and suicidality in the sample consisting of the general population and that traumatic events including stressful events become the cause for having dissociative experiences. Also, the study found that women had a higher score on the DES than the men and did not find any statistically significant relations between age and dissociation whereas, an earlier study by Seedat, Stein and Forde found that men had a higher score in the DES-T than women, but the scores declined withage.

Irwin (1999) conducted a research study which studied the relationship between childhood trauma and pathological and non-pathological dissociation. The sample used was that of Australian people, 50 men and 50 women between 18 and 58 years and that entailed a one on one administration of three questionnaires, namely, one asking for details of gender and age and the two other questionnaires were related to dissociative tendencies and childhood trauma measured using the Dissociative Experiences Scale (DES). The findings of the study were that pathological dissociation was positively related to and predicted by the various facets of 
childhood trauma but no such relationship was found for non-pathological dissociation or psychological absorption.

Stiglmayr et al (2010) conducted a study to develop a scale based on earlier studies conducted that found and stated that the phenomena of dissociation are not specific to childhood trauma alone. A sample of 294 male and female patients with Bipolar Disorder (BPD), Post Traumatic Stress Disorder (PTSD), anxiety disorder, major depression and schizophrenia was recruited and the psychometric properties of the scale was measured on them. The study found and provided validity and evidence for the DSS being a good instrument for assessing changing symptomatology and psychopathological and dissociative features over a period of time. The data is found to be consistent with the traumagenic model of the dissociative disorders but also found that other factors besides traumatic experiences during childhood also exist.

A research study conducted by Carlson, Dalenberg and McDade-Montez (2012) aimed at addressing the relation between traumatic stress and resulting dissociation; the increase in dissociation levels owing to stress resulting from traumatic experiences and the subsequent decline of the same over a gradual period of time; the relationship between dissociation and symptoms of PTSD in nonclinical, clinical, and PTSD samples; the conditional probability of high PTSD symptoms when dissociation level is high; the relationships among dissociation and re-experiencing, avoidance, and hyper arousal symptoms of PTSD; and biological studies of dissociation in PTSD. The researchers have based the study on researches conducted by other researchers in order to answer questions regarding the relation between dissociation and stress and the extent to which they are related. Reviews of the empirical literature provided sufficient evidence for dissociation being moderately related to trauma exposure and severity, that dissociation symptoms rise sharply immediately after trauma exposure, then gradually decline for most, but stay high for some; dissociation is clearly, consistently, and very strongly related to the presence and severity of DSM-IV Post Traumatic Stress Disorder (PTSD) symptoms and finally, the presence of high dissociation increases the probability of the presence and development of high levels of PTSD symptoms.

In a related study done by Ross, Joshi and Currie (1990) studied the existence of dissociative experiences as being fairly common among the general population and the decline in these experiences with age. The sampling procedure used was three stage random stratified samples and used a random cluster sample of 23 neighborhoods and households with residents of 18 years of age and above in Winnipeg, Canada. The tools used were the interview method with the administration of the Dissociative Experiences Scale (DES). The findings of the study conducted were that the level of dissociative experiences experienced by both males and females after the age of 18 years was common as well as equal. Men and women differed only on two items of the scale: women may tend to talk out loud to themselves more than men because they spend more time alone at home and men may forget important events such as anniversaries because of cultural reasons and because of sex role stereotyping. Also, 
spontaneous dissociative experiences were found to decline with age in the general population and appear to level off in the fourth decade.

\section{OCCUPATIONAL STRESS}

A study was also conducted by Chaturvedi, et al (2008) titled focused primarily on the screening for psychiatric caseness and identified the extent of anxiety, depression and distress problems in the Information Technology and Information technology Enabled Services (IT/ITES) sectors. 100 IT/ITES professionals were randomly selected and administered the General Health Questionnaire - 28 items scale (GHQ-28). The research findings for the study conducted by Chaturvedi et al (2008) showed that the rate of psychiatric morbidity is higher than that reported for the general population in India and suggests a need for health promotion activities in the IT sector.

In a related study conducted by Subramanian and Vinothkumar (2009) studied the assumption that enhancing the strengths of individuals ${ }^{e e}$ internal resources such as hardiness and selfesteem act as a buffer while encountering any stressful events in occupational life. 140 IT professionals from four software companies were selected and were administered the Occupational Stress Index, Hardiness Questionnaire and Rosenberg Self Esteem Scale. The implications of the study were that with possible intervention to improve internal resources among IT professionals their perceived levels of occupational stress can be minimized to the maximum extent possible.

A study conducted by Aziz (2004) studied the intensity of organizational role stress among female Informational Technology (IT) professionals in the Indian private sector. The study used a sample of 234 women from the IT sector to study the level of role stress at the workplace and the tool used to assess the level of stress was the Organizational Role Stress Scale. The research findings found that inadequate resources had emerged as the most potent role stressor, followed by role overload and personal feelings of inadequacy.

A field study conducted by Li and Shani (1991) titled "Stress Dynamics of Information Systems Managers: A Contingency Model” studied the relationship among organizational characteristics, job satisfaction and work stress. The sample used comprised of 109 Information Systems (IS) managers using tools used in existing literature. The findings showed that work overload is the main perceived cause for work stress, followed by factors such as role conflict, job-induced anxiety and role ambiguity. Also, contextual factors within the organization, such as climate, clarity in the mission of the organization, work life quality, and flexibility of organizational processes were found to significantly affect job satisfaction and as a result, work stress.

A study conducted by Deosthalee and Pravin (2000) examined the effect of gender, age variation and differences in level of educational qualifications on occupational stress 
experienced by engineers. The sample studied consisted of 198 engineers, both male and female, working in different organizations in Mumbai, India. The Occupational Stress Index (OSI) was used to obtain data. The results showed that although age had no effect on stress levels experienced by engineers, gender and level of education attained had a significant impact on the stress levels.

Also, it was found that male engineers experienced a higher level of stress than female engineers but it was also found that higher the level of education attained, the less the stress experienced by the engineers.

The studies conducted by Maaranen (2004), Irwin (1999) and Stiglmayr (2010) related to dissociation and the extent of dissociation as predicted by trauma over time support the present study by providing evidence for previous studies conducted to study pathological and nonpathological dissociation in the general population as well as population consisting of individuals suffering from depression, suicidality, alexithymia, childhood trauma etc. The studies reviewed have to some degree supported the fact that not all forms of dissociation are instigated by childhood trauma or past traumatic experiences and have causes residing in other factors as well. Development of the Dissociative Tension Scale by Stiglmayr et al (2010) has made the assessment of changing symptomatology also possible. The studies conducted by Carlson, Dalenbergand McDade-Montez (2012) and Ross, Joshi and Currie (1990) also studied the relation of dissociation and stress or trauma and how sufficient stress can activate dissociative symptoms and how it is a common phenomenon in the general population which declines with age showing that perhaps stress levels are expected to be higher at an earlier age than at a later stage in one $e^{\text {ec }}$ life. These studies display how the development of various scales to measure dissociative experiences can help identify psychological disturbances in an individual and help treat it as well as the various causes for dissociation to occur in an individual ranging from stress, to childhood abuse to post traumatic stress disorders etc.

The studies conducted by Chaturvedi et al (2008) and Subramanian and Vinothkumar (2009) on the detection of stress, anxiety and depression among IT professionals and the reduction of the impact of a stressful situation by enhancing hardiness and self-esteem of individuals are supportive of the present study in the sense that the two studies provide evidence for the existence of stress as a symptom for psychiatric illness in IT professionals. Similar to the aim of the present study, Chaturvedi et al (2008) have explored the cases of psychiatric illness and has implied the need for general health intervention in IT companies at large. In keeping with the aim of the study, the mentioned study supports the implication of the present study. Also the study by Subramanian \&Vinothkumar (2009) has displayed the various attempts made to reduce the extent of stress through health interventions such as enhancing personal individual resources like hardiness and self-esteem and the study conducted by Aziz, M. (2004), attached the factor of resource inadequacy to rising stress levels which may affect general wellbeing of the employees. The study by Li and Shani (1991) shows how factors such as role overload, role 
ambiguity and contextual factors like climate and clarity of the organization's missions affect job satisfaction and thereby, prove as a trigger for work related or occupational stress. Hence, the following studies display how stress levels involved in the occupational sphere of individuals can manifest themselves in the form of various disorders that threaten the wellbeing and biological, psychological and social aspects of the self. The study done by Deosthalee and Pravin (2000) show how stress levels, although not affected by age, is affected by gender and level of education.

Therefore, the studies mentioned above support the construct of the research study by providing norms and other data to go by. The above research articles also show the scope for improvement of occupational stress levels in IT professionals so as to reduce the impact of work induced stress leading to dissociation which is possible not only as a result of childhood trauma, past traumatic experiences or other pathological illness but also as a result of high or chronic stress emanating from the work environment of an individual.

\section{METHODOLOGY}

\section{Problem:}

To see if there is a relation between occupational stress levels and the presence of dissociative features among IT professionals and compare gender and age differences.

\section{Hypotheses:}

1. Stress levels are related to the presence of dissociative features in IT professionals.

2. There is no gender difference in occupational stress and dissociative features.

3. There is no age difference in occupational stress and dissociative features.

\section{Operational Definitions}

\section{Occupational Stress}

Occupational stress is defined as "A condition arising from the interaction of people and their jobs and characterized by changes within people that force them to deviate from their normal functioning." (Beehr and Newman,1978)

\section{Dissociation}

"Dissociation is a process whereby the mind separates one or more aspects of its function (knowing, feeling, tasting, hearing, seeing, etc.) away from the normal stream of consciousness.” (Hawkins,2009) 


\section{RESEARCH DESIGN:}

The research design used for the purpose of conducting the study is a quantitative research design. "Quantitative research is a formal, objective, systematic process in which numericaldata is used to obtain information about the world. It is used to describe variables, to examine the relations between them and to determine cause and effect interactions between the variables.” (Burns and Grove,2005)

The study is analyzed using the Pearson's Product-Moment correlational method to study the relation between stress levels and dissociative features in IT professionals and MannWhitney's U test, a non-parametric test to find age and gender differences. A correlational study is a quantitative method of research in which two or more quantitative variables from the same group of subjects are studied to determine if there is a relationship or co-variation between the two variables. The two types of correlation are positive correlation wherein if one variable increases or decreases, so does the second variable and vice versa and negative correlation wherein if one variable increases, the second variable decreases or vice versa. Pearson's Product-Moment correlation is the ratio of covariance between two variables of the standard deviation of one variable to the standard deviation of the other variable. MannWhitney $\mathrm{U}$ test is a non-parametric statistical test used to find out if one of the two independent sample observations tends to have larger values than the other.

\section{Sample:}

The sample selected for the study is a sample of 50 IT professionals from a few IT companies in Bangalore. The sample of IT professionals was chosen from well-recognized IT companies through the method of convenience sampling which is a type of non-probability sampling which involves the sample being selected from the population that is most convenient to pick or choose from at a given point in time, i.e., a sample population is selected because it is readily available and convenient.

The inclusion criteria for the sample are:

- $\quad$ The sample must include individuals between the ages of 25 and 35.

- $\quad$ They must be able to read and write in English.

- $\quad$ They must be residing in Bangalore.

The exclusion criteria for the sample are:

- $\quad$ The sample must not consist of any non-nationals. 


\section{Method of Data collection:}

The method used to collect data is the survey method. It studies the sampling of IT employees and uses statistical inferences to make conclusions about the effect of stress levels on the wellbeing of IT professionals.

\section{Tools used:}

The tools used are as follows:

- $\quad$ Occupational Stress Index (OSI) (Srivastav and Singh, 1981) to study stress levels in the employees of the company. It purports to measure the extent of stress which employees perceive arising from various constituent and conditions of their job.

- $\quad$ Dissociative Experiences Scale II (DES II) (Bernstein and Putnam, 1993) to further determine the extent to which stress levels impact the frequency of dissociation. It is a selfassessment questionnaire that measures dissociative symptoms. (Bernstein and Putnam,1986).

\section{Scoring:}

The Occupational Stress Index (OSI) consists of 46 items, each to be rated on the five-point scale. It consists of both true keyed and false keyed items, 28 true keyed items and 18 false keyed items; hence, two different patterns of scoring have to be adopted for the two types of items.

Based on the response given by the individual, scores are given for each option chosen for the true keyed and false keyed items. Scores falling above $\pm 1 \sigma$, between $\pm 1 \sigma$ and below $\pm 1 \sigma$ are categorized based on the individual scores, respectively as high, moderate and low levels of occupational stress. The reliability of the index as a whole determined by split half method and Cronbach $^{\text {ee }}$ s alpha-coefficient is .935 and .90 respectively. The employees ${ }^{\text {ee }}$ scores on the OSI have been found to be positively correlated with their scores on the measures of mental ill health.

The Dissociative Experiences Scale II consists of 28 items to be rated by the individual. The DES score is obtained by summing item score and dividing it by 28 (the total number of items).

Overall scores range from 0-100. Scores of 30 or above warrant further psychological evaluation, however they do not necessarily reflect the level of psychopathology since some DES items ask about non-pathological forms of dissociation. The test-retest reliability for the scale is .93 for the total DES score and .95, .89, and .82 for the three subscale scores of amnesia, depersonalization- derealisation, and absorption [dissociative identity disorder (DID)]. 


\section{PROCEDURE:}

A sample of 50 IT professionals was selected from an IT company in Bangalore. The sample was obtained using convenience sampling and snowball sampling techniques with the help of relatives working in the better known IT companies in Bangalore who helped in the collection of data by giving out the questionnaires to their colleagues in their respective companies consisting of the Informed Consent form, the Occupational Stress Index and the Dissociative Experiences Scale.

The employees were given the Occupational Stress Index (OSI) and the Dissociative Experiences Scale II (DES II) and were asked to answer it honestly as part of the study. These scales were used for the purpose of finding out the extent to which participants with high stress levels were perceived as having dissociative features by correlating the occupational stress scores obtained on the OSI with the scores obtained on the DES, thereby, indicating the level of dissociation.

\section{Data Analysis:}

The data obtained is analyzed using descriptive statistics. Descriptive statistics is the discipline of quantitatively describing the main features of the collection of a set of data. (Mann and Prem, 1995).Descriptive statistics provides simple summaries about the sample distribution and about the observations that have been made. It summarizes data either using simple statistics or through visual means like bar diagrams, pie charts etc.

The degree of dissociation in the sample in relation to the identified levels of occupational stress is analyzed using method of correlation, specifically Pearson's product moment correlation method to determine the relation between stress levels and presence of dissociative features. Pearson's product moment correlation is used when both the criterion (dissociative features) and predictor (stress levels) variables contain continuous interval data.

\section{Ethical Considerations:}

The ethical considerations of the concerned study were:

- To maintain the anonymity and confidentiality of the participants.

- The participants were given an informed consent form before giving their consent to be a part of the survey and were briefed about the aim of the study. The informed consent consisted of brief information about the study and the consent of the concerned individual to being a part of the study on a purely voluntary basis.

- The participants were asked to provide only their initials for the sake of protecting their identity.

- The participants were granted permission to leave the survey if they were uncomfortable being a part of it. 
- The participants were told about their results if they wanted more information regarding the implications of the study for them.

\section{RESULTS AND DISCUSSION}

The present study was conducted for the purpose of studying the levels of occupational stress originating at the workplace in the IT industry and exploring the effect of the same on the tendency of the employees to experience dissociation from their immediate surroundings physically and emotionally. The sample used for the purpose of conducting this study consisted of 50 IT professionals, both males and females, collected through convenience and snowball sampling techniques. The tools used to obtain data were the Occupational Stress Index (OSI) developed by Srivastav and Singh in 1991 and the Dissociative Experiences Scale II (DES II) developed by Bernstein and Putnam in 1993. The aim and the objectives of the study was to assess the stress levels of IT professionals, to explore the presence of dissociative features in IT professionals and to study the relation between stress levels and the presence of dissociative features in IT professionals, the hypotheses being that:

- $\quad$ Stress levels are related to the presence of dissociative features in IT professionals.

- $\quad$ There is no gender difference in occupational stress and dissociative features.

- $\quad$ There is no age difference in occupational stress and dissociative features.

Quantitative research methodology was used to conduct the study. Pearson's product-moment correlation was used to find the level of correlation between the occupational stress levels of IT workers and the presence of dissociative features. Also, descriptive and inferential statistics were employed to find out the spread of the two variables among the sample population and the significance of gender and age differences among them. The sample was divided on the basis of gender and age for this purpose and the spread of the levels of occupational stress and dissociative experiences (high and low) was done using Mann-Whitney"s $U$ test and was displayed using tables and graphical representations.

\section{Sample distribution}

\section{Table4.1 Showing the distribution of the sample}

\begin{tabular}{|c|c|c|}
\hline & Categories & No. \\
\hline Gender & Males & 32 \\
\hline & Females & 18 \\
\hline Age & $25-30$ & 39 \\
\hline & $31-35$ & 11 \\
\hline
\end{tabular}


The sample for the study was obtained through employment of convenience sampling and snowball sampling techniques. The total sample used was 50 IT professionals, 32 males and 18 females, between the ages of 25-35, from IT companies located in Bangalore. The sample was chosen based on the assumption that the IT industry, rather, the IT capital of India, Bangalore, would be the industry comprising of workers with the maximum amount of occupational stress, owing to the demanding nature of the job, long working hours and amount of work. Keeping this in mind, the sample was chosen from among some of the well-known companies in the city.

\section{Description of Gender Differences In Stress And dissociation}

Table4.2 Showing the spread of levels of occupational stress and dissociative features among males and female $(n=50)$

\begin{tabular}{|l|c|c|c|c|}
\hline Gender & OSI (High) & OSI (Low) & DES (High) & DES (Low) \\
\hline Male & 5 & 27 & 7 & 25 \\
\hline Female & 2 & 16 & 1 & 17 \\
\hline
\end{tabular}

Figure4.1, Showing the spread of levels of occupational stress and dissociative features among males and female $(n=50)$

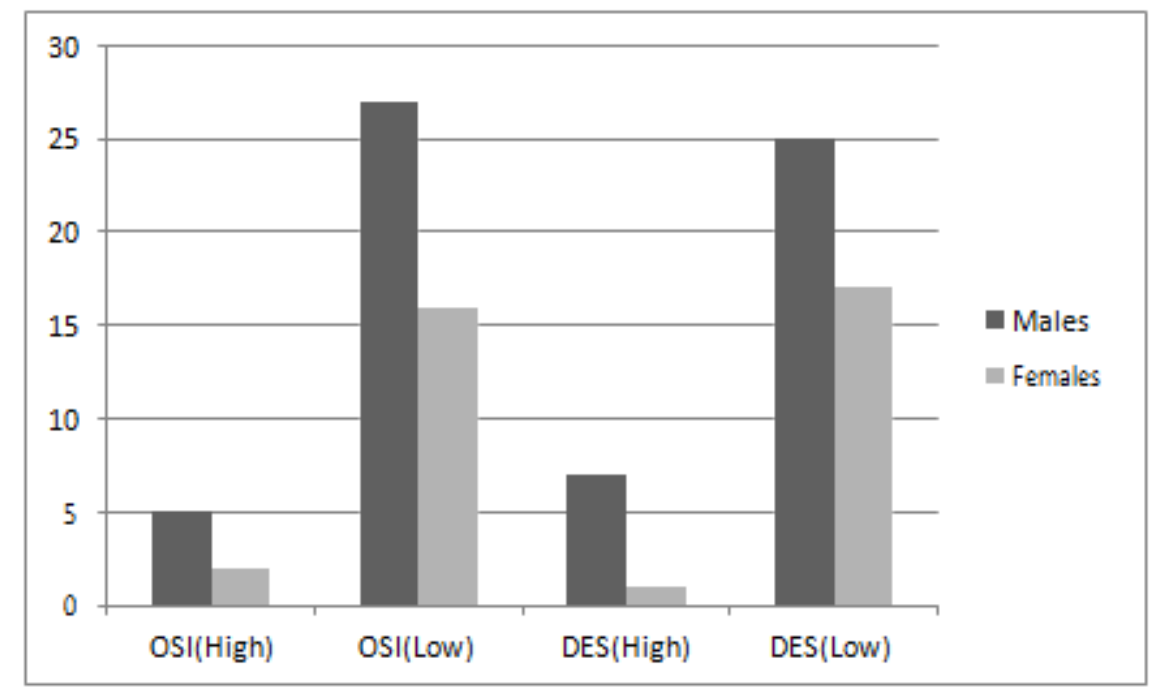

It is found from the table that of the sample studied by the present population, of the male population, 5 males had high levels of occupational stress and 27 had low levels of occupational stress. Of the female population, 2 females had high levels of occupational stress and 16 of them had low levels of occupational stress. Of the entire population, 7 males had high levels of dissociative experiences while 25 of them had low levels of dissociative 
experiences. Similarly, of the female sample population, only 1 female was found to have high levels of dissociative experiences while 17 of them had low levels of dissociative experiences. The study aimed at finding, as one of the objectives, a comparison between males and female sin terms of occupational stress experienced and the effect of the same on the levels of dissociation experienced.

From the data collected it was found that of the 12 subscales of the Occupational Stress Index (OSI) on which the majority of the population had a high score, were related to factors such as Role Overload, Role Conflict, Unreasonable Group and Political Pressure, Intrinsic Impoverishment, Strenuous Working Conditions and Unprofitability. Role overload indicates the excessive amount of work that is demanded of the individual that may cause disruptions in other spheres of his/her life. Role conflict indicates the ambiguous nature of one's work and the lack of sufficient instructions and facilities relating to one's work. Unreasonable group and political pressure indicates that the individual's quality and quantity of work is affected strongly by group and political pressure. Intrinsic impoverishment indicates the extent to which an individual is given ample opportunities to learn on the job and improve in terms of aptitude and proficiency.

Strenuous working conditions refer to the tiresome nature of the job that may hinder a person "overall wellbeing both at and outside of the work environment. Findings of a study conducted by Deosthalee and Pravin (2000) stated that male engineers experienced higher occupational stress levels than did female engineers, thereby, also supporting the similar findings of the present study wherein it was found that male IT professionals had a higher level of occupational stress as caused by the various factors assessed by the Occupational Stress Index(OSI).

From the data collected it was observed that the population differed in scores on the 3 factors assessed by the Dissociative Experiences Scale (DES), namely, Amnesia Factor, Depersonalization/Derealisation Factor and Absorption Factor. Certain questions on the questionnaire evaluated a person on the basis on these 3 factors in order to find out the problem area.

Amnesia factor measures memory loss, including events like not being able to remember how one got somewhere, being dressed in clothes one doesn't remember putting on, not recognizing friends and family, finding evidence of having done things one doesn't remember having done etc.

Depersonalization/derealisation factor involves the feeling or experience of being detached from one's self and other mental processes or a sense of watching oneself that leads to the feeling of unreality. It measures this detachment from self, including events like getting the 
feeling that one is standing next to themselves or watching themselves, feeling of one's body as not belonging to them, looking in a mirror and not recognizing yourself etc.

Absorption factor measures the tendency to get so involved and preoccupied with doing something that one becomes unaware of happenings around them. It has to do with one $\mathrm{s}$ traumatic experiences. It involves events like remembering a past event so vividly that it feels as though one is reliving the event, not being sure whether the things they remember happening really did happen or they merely dreamed them, becoming so absorbed in a story that one is not aware of the events happening around them etc.

Majority of the male population was found to be higher on the amnesia factor and were found to be moderate on the absorption and depersonalization factors. According to the findings of a study conducted, although women were found to be higher on overall dissociation levels than men, it was also found that men had obtained a higher mean score on the amnesia factor than women, lower mean score on the absorption factor and depersonalization/derealization factor as compared to women (Maaranen,2004).

The high mean score on the amnesia factor as in the case of the sample could be directly related to the levels of occupational stress faced by the sample. The factors contributing to occupational stress such as role overload, role conflict and strenuous working conditions could be seen as the causal factors for a person becoming preoccupied with their work, thereby, not paying much attention to events and other such minute details and hence, tend to have memory lapses when recalling them.

\section{Description of Age Differences In Stress And dissociation}

Table 4.3m Showing the spread of levels of occupational stress and dissociative features among the different age groups (25-30 and31-35)

\begin{tabular}{|l|c|c|c|c|}
\hline Age Groups & OSI (High) & OSI (Low) & DES(High) & DES(Low) \\
\hline $\mathbf{2 5 - 3 0}$ & 7 & 32 & 5 & 34 \\
\hline $\mathbf{3 1 - 3 5}$ & 0 & 11 & 2 & 9 \\
\hline
\end{tabular}


Figure 4.2, Showing the spread of levels of occupational stress and dissociative features among the different age groups (25-30 and31-35)

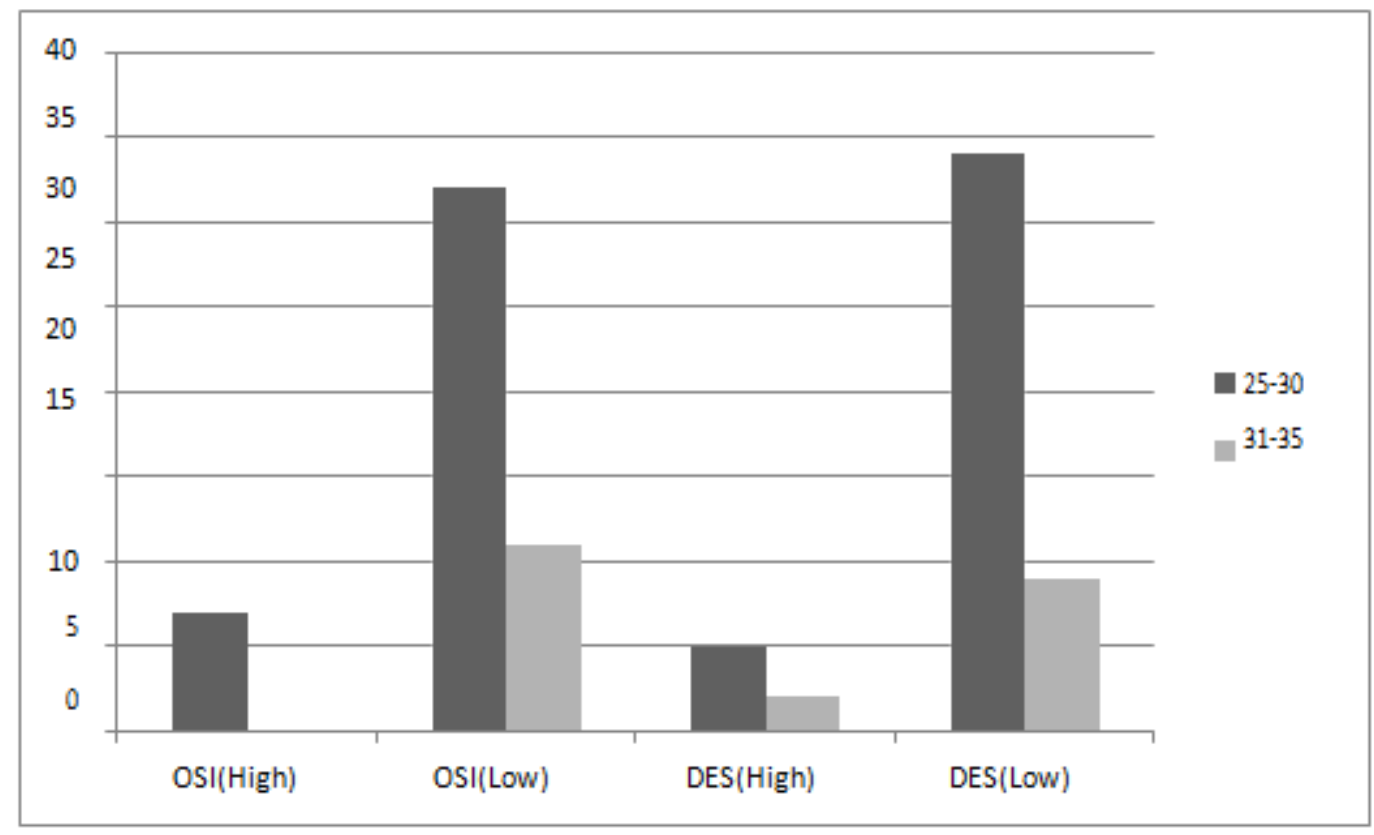

It is found from the table that of the sample studied by the present population, 25-30 year olds were found to have higher levels of both occupational stress as assessed by the Occupational Stress Index (OSI) as well dissociative features as assessed by the Dissociative Experiences Scale II (DESII).

The study aimed at finding, as one of it ${ }^{\text {ee }}$ s the objectives, a comparison between males and females in terms of occupational stress experienced and the effect of the same on the levels of dissociation experienced.

From the data collected, it was found that majority of the population with high levels of occupational stress were between the ages of 25 and 30 years. Also, of the 12 subscales of the Occupational Stress Index, the factors that contributed to high stress levels in this particular age group were Role Overload, Role Conflict, Unreasonable Group and Political Pressure, Intrinsic Impoverishment, Strenuous Working Conditions and Unprofitability. Factors such as Role Overload, Role Conflict and Strenuous Working Conditions were found to be the factors majority of the population had obtained high scores on. Findings of a study done by Deosthalee and Pravin(2000) showed that age had no effect on stress levels in engineers whereas, the findings of this study show that the sample population falling in the age group of 25-30 year olds has a higher level of occupational stress than those falling in the 31-35 year age group. The reason for this could also be attributed to the lower number of sample in the age group of 31-35 year olds, which is a major limitation of the present study. 
Based on the 3 subscales of the DES, namely, amnesia factor, depersonalization/derealisation factor and absorption factor, the people falling under the 25-30 year age group were found to have higher scores on the absorption factor. The absorption factor assesses to what extent a person gets absorbed or involved in some activity that they become completely oblivious to their surroundings and are unaware of what is happening around them. The reason for the same can be attributed to the demanding nature of work faced by IT professionals that leads them to get involved or absorbed in what they re doing owing to various work related factors such as role overload, tedious working conditions etc. and are hence, more prone to dissociating in certain situations. The findings of the study by Maaranen (2004) also support the present studye's findings. Similarly, in another study conducted by Ross, Currie and Joshi (1990), the findings of the study conducted were that dissociative experiences were equally common in men and women at all age levels from 18 years onward.

\section{Relation between Occupational Stress and dissociation}

Table 4.4, Showing the correlation values between Occupational stress and Dissociative experiences using Pearson's Product-Moment Correlation

\begin{tabular}{|c|c|c|c|}
\hline & & OSI & DES \\
\hline \multirow[t]{3}{*}{ OSI } & PearsonCorrelation & 1 & 0.27 \\
\hline & Significance (2-tailed) & $0.05^{*}$ & \\
\hline & $\mathbf{N}$ & 50 & 50 \\
\hline \multirow[t]{3}{*}{ DES } & PearsonCorrelation & 0.27 & 1 \\
\hline & Significance(2-tailed) & $0.05^{*}$ & \\
\hline & $\mathbf{N}$ & 50 & 50 \\
\hline
\end{tabular}

After having obtained the required data in the form of occupational stress scores and dissociative experiences scores, Pearson "es product-moment correlation was used to find out the level of correlation between stress levels and dissociation. Analysis of data led to the finding that the data was significant at 0.05 levels and that there is a positive correlation between stress levels and dissociation. Therefore, the first hypothesis that stress levels are related to the presence of dissociative features among IT professionals is proven. Findings from a study 
conducted in 2004, has found that dissociative experiences are not related to only depression, alexithymia and suicidality but also due to stressful events (Maaranen, 2004). The correlation values between occupational stress and dissociative features in the present study support the findings of previous literature, thereby, proving that there is relation between occupational stress levels and dissociative features among the IT professionals in the sample.

V Gender Differences in Occupational Stress among Male And Female IT professionals

Table 4.5 Showing the mean rank and Mann-Whitney U scores on occupational stress of males and females

\begin{tabular}{|c|c|c|c|c|c|c|}
\hline$(n=50)$ & & & & & & \\
\hline & Gender & Number & Mean & Sum of & Mann- & Significance \\
\hline \multirow{3}{*}{ OSI } & & & Rank & Ranks & Whitney U & (2-tailed) \\
\hline & Male & 32 & 25.25 & 808 & 280 & 0.87 \\
\hline & Female & 18 & 25.94 & 467 & & \\
\hline
\end{tabular}

The table shows that there is no statistically significant gender difference in occupational stress levels experienced (.87) as found Mann-Whitney's U test. This indicates that there isn't a significant difference in terms of the occupational stress experienced by men and women. The reason for the same can be attributed to the fact that women are also entering into the work sphere now and joining organizations with job positions that are at par with those held by men and are hence, at equal risk of experiencing high levels of occupational stress.

Factors such as Role Overload, Role Conflict, Unreasonable Group and Political Pressure, Intrinsic Impoverishment, Strenuous Working Conditions and Unprofitability were found to be the common reasons for high levels of occupational stress as experienced by both male and female IT professionals. Hence, the gender difference within the sample population in regard with occupational stress levels is not statistically significant. Findings of a study conducted by Deosthalee and Pravin (2000) stated that male engineers experienced higher occupational stress

levels than did female engineers, thereby, also supporting the similar findings of the present study wherein it was found that male IT professionals had a higher level of occupational stress as caused by the various factors assessed by the Occupational Stress Index(OSI). 


\section{Gender Differences in Dissociative Experiences among Male and Female It professionals}

Table 4.6 Showing the mean rank and Mann-Whitney $U$ scores on dissociative experiences of males and females $(n=50)$

\begin{tabular}{|ll|c|c|c|c|c|}
\hline \multirow{2}{*}{ Gender } & Number & $\begin{array}{c}\text { Mean } \\
\text { Rank }\end{array}$ & $\begin{array}{c}\text { Sum of } \\
\text { Ranks }\end{array}$ & $\begin{array}{c}\text { Mann- } \\
\text { Whitney } \\
\text { U }\end{array}$ & $\begin{array}{c}\text { Significance } \\
\text { (2-tailed) }\end{array}$ \\
\hline \multirow{2}{*}{ DES $\quad$ Male } & & 32 & 29.05 & 929.50 & 174.500 & 0.02 \\
\cline { 2 - 6 } & Female & 18 & 19.19 & 345.50 & & \\
\hline
\end{tabular}

The table shows that gender difference in dissociation levels experienced is significant at the 0.05 level (0.02) as found Mann-Whitney's U test. This indicates that the gender difference in terms of dissociative experiences is significant, i.e., the male population was found to have a higher level of dissociation and related experiences than the female population.

From the data collected, it was observed that the male population of the sample experienced a higher level of dissociation than did the female population. Of the 3 factors measured by the Dissociative Experiences Scale, men were found to have a higher score on the Amnesia factor than the women, and were found to have a lower score on Depersonalization/derealization factor and Absorption factor. Hence, the gender difference within the sample population in regard with dissociative experiences is statistically significant.

Hence, the second hypothesis, that there are no gender differences in occupational stress and dissociative features is partially proven as there is no statistical significance between gender and occupational stress whereas there is a significant difference between gender and dissociative features. According to the findings of a study conducted, although women were found to be higher on overall dissociation levels than men, it was also found that men had obtained a higher mean score on the amnesia factor than women, lower mean score on the absorption factor and depersonalization/derealization factor as compared to women (Maaranen,2004). 


\section{Age Differences In Occupational stress}

Table 4.7, Showing the mean ranks and Mann-Whitney's U scores on occupational stress of the different age groups (25-30 \&31-35)

\begin{tabular}{|cc|c|c|c|c|c|}
\hline & $\begin{array}{c}\text { Age } \\
\text { Groups }\end{array}$ & Number & $\begin{array}{c}\text { Mean } \\
\text { Rank }\end{array}$ & $\begin{array}{c}\text { Sum of } \\
\text { Ranks }\end{array}$ & $\begin{array}{c}\text { Mann- } \\
\text { Whitney U }\end{array}$ & $\begin{array}{c}\text { Significance } \\
\text { (2-tailed) }\end{array}$ \\
\hline \multirow{2}{*}{ OSI } & $25-30$ & 39 & 26.95 & 1051 & 158 & 0.185 \\
\cline { 3 - 7 } & $31-35$ & 11 & 20.36 & 224 & & \\
\hline
\end{tabular}

The table shows that there is no statistically significant age difference in occupational stress levels experienced (.185) as found Mann-Whitney’s U test. This indicates that there isn’t a significant difference in terms of the occupational stress experienced people in the age group of 25-30 years and 31-35years.

The findings of this study show that the sample population falling in the age group of 25-30 year olds has a higher level of occupational stress than those falling in the 31-35 year age group. The reason for this could also be attributed to the lower number of sample in the age group of 31-35 year olds, which is a limitation faced by the present study. Hence, the age difference within the sample population in regard with occupational stress levels is not statistically significant.

\section{Age Differences In Dissociative experiences}

Table 4.8, Showing the mean ranks and Mann-Whitney's scores on dissociative experiences of the different age groups (25-30 \&31-35)

\begin{tabular}{|cc|c|c|c|c|c|}
\hline & $\begin{array}{c}\text { Age } \\
\text { Groups }\end{array}$ & Number & $\begin{array}{c}\text { Mean } \\
\text { Rank }\end{array}$ & $\begin{array}{c}\text { Sum of } \\
\text { Ranks }\end{array}$ & $\begin{array}{c}\text { Mann- } \\
\text { Whitney U }\end{array}$ & $\begin{array}{c}\text { Significance } \\
\text { (2-tailed) }\end{array}$ \\
\hline \multirow{2}{*}{ DES } & $25-30$ & 39 & 25.32 & 987.50 & 207.50 & 0.870 \\
\cline { 2 - 7 } & $31-35$ & 11 & 26.14 & 287.50 & & \\
\hline
\end{tabular}

The table shows that there is no statistically significant age difference in occupational stress levels experienced (.185) as found Mann-Whitney's U test. This indicates that there isn't any statistically significant age difference between the two age groups (25-30 and 31-35) in terms of the level of dissociative experiences. 
From the data collected, it was observed that the majority of the population in the age group of 25-30 year olds was found to have a high score on the Amnesia factor, which assesses the individual's memory of certain dates and events, as well as the Absorption factor, which assesses the extent to which an individual gets so absorbed or involved in something that they're doing that they become unaware of their surroundings.

Hence, the third hypothesis, that there are no age differences in occupational stress and dissociative experiences is proven as there is no statistical significance between age and occupational stress nor age and dissociative features.

The findings of the study support the findings of a study conducted by Maaranen (2004) which found that pathological dissociation is caused not only by feelings of depression, alexithymia or suicidality but also due to stressful events as proven by the present study as well in finding that stress arising from the work sphere contributes to the increase in presence of dissociative features among employees. Also, the findings supplement findings of a study conducted by Chaturvedi et al (2008) which found that psychological morbidity was higher in IT professionals as found by the levels of dissociation and caseness in the sample.

\section{SUMMARY AND CONCLUSION}

The present study aimed at finding the effect of occupational stress on the presence of dissociative features among IT professionals and also to explore the gender and age dimensions of those variables. It was hypothesized that there is a relation between stress levels and the presence of dissociative features, that there are no gender differences in occupational stress and dissociative features and that there are no age differences in occupational stress and dissociative features. The sample used to test these hypotheses on was a sample of 50 persons, both male and female, from a few well-known IT companies in the city of Bangalore, India. The data collected was analyzed using Pearson's product-moment correlation to determine the relation between occupational stress and dissociative features, and Mann-Whitney's U test was used to determine if there was statistical significance in terms of gender and age differences.

\section{MAJOR FINDINGS OF THE STUDY:}

- There is a positive significant correlation between stress levels and the presence of dissociative features, thereby, proving the first hypothesis that there is a relation between occupational stress and the presence of dissociative features.

- $\quad$ There are no statistically significant gender differences in occupational stress, but gender differences in dissociative features are statistically significant, thereby, partially proving the second hypothesis that there are no gender differences in occupational stress and dissociative experiences. 
- There are no statistically significant age differences in occupational stress and dissociative features, thereby, proving the third hypothesis that are no age differences in occupational stress and dissociative features.

\section{LIMITATIONS OF THE STUDY:}

- The study does not take into consideration the economic background of the participants and the effect of their financial status on stress in the occupational sphere, which in turn could affect the dissociative experiences.

- The job positions held by the participants of the study are not taken into account, which may affect the level of stress.

- The sample used is uneven in terms of gender and age distribution which may affect the nature of the results.

\section{IMPLICATIONS OF THE STUDY:}

- The study seeks to identify cultural relevance of the psychological phenomenon of dissociation as research on the same is very limited in the Indian context.

- It also has the potential to expand research on the non-pathological features of dissociation which is still a developing construct.

- It may also help IT companies recognize the need for psychiatric intervention or general health or self-esteem building strategies depending on the extent of dissociation observed among employees (low, moderate, high or pathological dissociation).

\section{SCOPE FOR FURTHER RESEARCH:}

- The study was restricted only to the IT industry in Bangalore and can also be applied to other job fields.

- The present study provides more scope for further research in the field of dissociation as well as stress related dissociation in multiple industries and work fields.

- It has the ability to pave way for developing psychiatric as well as psychosocial rehabilitation programmes by organizations as part of employee welfare as well as to improve the organization's credibility and productivity.

- It can be used in various organizations as an intervention programme that could help make adjustments to structure, strategies, management etc. depending on the findings (based on age groups, job positions, etc.).

- The present study also helps identify cases of dissociation which may go unnoticed owing to the limited information available about it culturally and lack of general awareness about the various facets of mental health awareness, and provide appropriate treatment at the earliest. 


\section{REFERENCES}

Aziz, M., (2004).Role stress among women in the Indian information technology sector.Women in Management Review, 19 (7), 356 -363.

Beehr, T.A. \& Newman, J.E. (1978). Job stress, employ health and organizational effectivenessA fact analysis model and literature reviews. Personal Psychology, 31,665-669.

Bernstein, E. M., \& Putnam, F. W. (1986). Development, reliability and validity of a dissociation scale.Journal of Nervous and Mental Disease, 174,727-735.

Bremner, J. D., \& Brett, E. (1997).Trauma-related dissociative states and long-term psychopathology in posttraumatic stress disorder. Journal of Traumatic Stress, 10,37-50.

Bremner, J.D., Koopman, C., Classen, C., \& Spiegel, D. (1994). Predictors of posttraumatic stress symptoms among survivors of the Oakland/Berkeley, California, firestorm. American Journal of Psychiatry, 151,888-894.

Burns, N. \& Grove, S.K., (2005).The practice of nursing research: Conduct, critique, and utilization (5th Ed.). St. Louis, Elsevier Saunders.

Carlson, E. B., Dalenberg, C., \&McDade-Montez, E. (2012).Dissociation in posttraumatic stress disorder part I: Definitions and review of research. Psychological trauma: Theory, research, practice, andpolicy.

Chaturvedi, S.K., Kalyansundaram, S., Jagadish, A., Prabhu, V. \&Narasimha, V.(2008).

Detection of stress, anxiety and depression in IT/ITES professionals in the Silicon Valley of India: A preliminary study. Primary Care \& Community Psychiatry, Vol. 12(2),75-80.

Dell,P.F.,\&O Neil,J.A.(2009).Dissociationandthedissociativedisorders:DSM-Vand beyond.

Foote, J. B., Smolin, Y., Neft, D. I., \& Lipschitz, D. (2008). Dissociative disorders and suicidality in psychiatric outpatients. Journal of Nervous and Mental Disease, 196, 2936.

Deosthalee \& Pravin, G. (2000). Effect of gender, age and educational maturity on job stress. Psycho-Lingua, 30(1),57-60.

Henry, O. \& Evans, A.J. (2008).Occupational stress in organization. Journal of Management Research 8(3),123-135.

Irwin, H.J. (1999). Pathological and Non-Pathological dissociation: The relevance of Childhood trauma. The Journal of Psychology, 133(2),157-164.

Mann \&Prem, S. (1995).Introductory Statistics, 2ndEdition,Wiley.

Maaranen P. (2004). Factors associated with pathological dissociation in the general population. Australian and New Zealand Journal of Psychiatry 2005;39:387-394

Morgan, C. A., Hazlett, G., Wang, S., Richardson, E. G., Schnurr, P., \& Southwick, S. M.(2001). Symptoms of dissociation in humans experiencing acute, uncontrollable stress: A prospective investigation. The American Journal of Psychiatry, 158, 1239-1247.

Stress at work (1999). U.S. National Institute for Occupational Safety and Health. DHHS (NIOSH) Publication Number 99-101. Retrieved from http://www.cdc.gov/niosh/docs/99- 101/

Ross, C. A., Joshi, S., \& Currie, R. (1990).Dissociative experiences in the general population. American Journal of Psychiatry, 147,1547-1552. 
Seedat, S., Stein, M.B., \& Forde, D.R..(2003). Prevalence of dissociative experiences in the community sample. Relationship to gender, ethnicity, and substance use. Journal of Nervous and Mental Disease, 191,115-120.

Steinberg, M., Rounsaville, B., \& Cicchetti, D. V. (1990). The structured clinical interview for DSMIII-R dissociative disorders: Preliminary report on a new diagnostic instrument. American Journal of Psychiatry, 147,76-79.

Stiglmayr, C., et al (2010). Development and psychometric characteristics of the dissociation tension scale. Journal of Personality Assessment, 92(3),269-277.

Subramanian, S., \&Vinothkumar, M. (2009).Hardiness personality, self-esteem and occupational stress among IT professionals. Journal of the Indian Academy of Applied Psychology, 35, 48- 56.

Thomas, W., Colligan, M.S.W., \& Higgins, M. (2006).Workplace stress. Journal of Workplace Behavioural Health.21(2),89-97.

Zlotnick, C., Shea, M. T., Pearlstein, T., Simpson, E., Costello, E., \& Begin, A. (1996).The relationship between dissociative symptoms, alexithymia, impulsivity, sexual abuse, and self- mutilation. Comprehensive Psychiatry, 37,12-16.

Zuboff, S. (1985). Automate/inform ate: the two faces of intelligent technology. Organizational Dynamics,4-18. 